\title{
UNDERGRADUATE STUDENTS' PERCEPTIONS ON EXTENSIVE READING STRATEGY IN VOCABULARY CLASS
}

\author{
Kristian Wijaya \\ SANATA DHARMA UNIVERSITY \\ Kristianwijaya500@gmail.com
}

\begin{abstract}
Vocabulary is one of the essential elements of English Language Teaching. It is therefore important to ensure that the students are able to obtain sizable vocabulary knowledge during their academic performance. Extensive reading strategy played a major role in that process. Two research problems were proposed in this study. The first is to know the effectiveness of extensive reading strategy in vocabulary class. The second is to discover the significant improvement of English Language Education students' vocabulary knowledge through extensive reading strategy. In this qualitative study, three research instruments: observation, classroom survey, and focus group discussion were employed. Qualitative content analysis was implemented to draw meanings out of the data gathered. Five major findings were as follows: (a) ELESP students viewed vocabulary as an important element in English language mastery (b) Loved reading extensively (c) Had limited time to read (d) Lose their reading motivation easily (e) Suggested regular checking of vocabulary books.
\end{abstract}

Keywords: Vocabulary, Extensive Reading Strategy, Qualitative Content Analysis

\section{INTRODUCTION}

Learning English cannot be separated from vocabulary since it determines EFL learners' success in acquiring the target language. Vocabulary is the heart of English language since the learners will not be able to produce any utterances, listen well, read effectively, and create good pieces of writing if they do not have enough vocabulary in their mind. However, language teachers think that vocabulary can be learned independently by the learners. Gardner (2004) states EFL teachers are accustomed to teaching English to their learners by applying an old teaching method which only requires less attention to vocabulary. Due to this fact, language teachers have strong reasons that they can abandon vocabulary learning when teaching the target language to their learners in the past.

As time goes by, many language teachers believe that conducting vocabulary teaching-learning processes to the learners is extremely important for it makes their learners become proficient English learners. Alqahtani (2015) - argues there is a close correlation between vocabulary knowledge and language use since vocabulary ease the language use and similarly, language use improve the amount of words. In relation to the importance of vocabulary learning, this research is aimed to investigate more about the implementation of extensive reading strategy in vocabulary class for the researcher believes reading is one of the essential skills which should be learnt and mastered by EFL learners in every language classroom setting with a purpose enabling them to recognize some important elements forming in their texts such as main idea, vocabulary, language styles, and whole information written by the authors. Extensive reading strategy played an important role in improving English Language Education students' vocabulary knowledge for this strategy is one of the most effective vocabulary learning 
strategies, which can promote some new words to EFL learners by assigning them to read their texts or books which they favor. cited in Day (2015) states extensive reading strategy has one clear objective namely the learners are allowed to read their favorite texts constantly in order to enrich their vocabulary knowledge.

Accordingly, language teachers need to be more thoughtful in selecting the appropriate teaching methods while implementing extensive reading strategy to their learners. Benettayeb (2010) states that EFL teachers should ensure that their vocabulary teaching method can be presented in various ways by integrating many kinds of vocabulary learning's activities in order to fulfill the learners' needs successfully. Further, language teachers can accomplish this challenging task by focusing more on their learners' vocabulary growth through the texts which they have chosen deliberately. Benettayeb (2010) argues language teachers should put their concern more on vocabulary in teaching the target language to the learners since learning a language does not merely talk about structure but also lexical items. In line with the aforementioned conception, there are four recent relevant studies done by the experts in Indonesia dealing with particular methods utilized to teach vocabulary. The first study was undertaken by Asyid, Nurdiansyah, and Parmawati (2019). They discovered that EFL learners were able to enrich their vocabulary more efficiently through color-coding technique since a higher degree of enjoyment and motivation assisted them to memorize some challenging words. Another interesting study was also accomplished by Anwar and Efransyah (2018). They found that crossword puzzle game increased EFL learners' perseverance and eagerness to expand their second language words mastery continuously since the learners did not get bored easily while engaging in this game. In another study, Parmawati (2019) found that magic sentence activity was helpful to erect more robust self-confidence in EFL learners. This positive learning outcome occurred since the learners experienced more enjoyable vocabulary learning activities prompting them to memorize as many new words as possible. The ultimate interesting study was done by Gayanti and Satriani (2020). They discovered that total physical response promoted more proactive engagement for EFL learners engaging in vocabulary class since a higher degree of anxiety was completely banished when uttering some new words. Four prior studies clearly showed that more enjoyable and interesting EFL teaching methods successfully assisted EFL learners to improve their vocabulary mastery in such a creative, unique, and innovative way. However, there were only few studies conducted to delve about the utilization of extensive reading strategy in improving EFL learners' vocabulary, particularly in Indonesia EFL learning processes. To fill this gap, this present study was conducted to discover undergraduate students' perceptions on extensive reading strategy in vocabulary class. Two research problems were proposed in this study namely:

(1) How did extensive reading strategy employ in the vocabulary class improve students' vocabulary?

(2) How did extensive reading strategy increase students' vocabulary knowledge?

\section{METHOD}

This qualitative study applied qualitative content analysis to obtain more accurate data. Each categorization process was enacted to provide better depictions for each phenomenon occurred in the designated research site. Moretti and Alessandrini (2015) argue that qualitative content analysis aims to create better generalizations for every single data categorized by the researchers. The participants of this study were English Language Education Students semester 2, Sanata Dharma University, engaging in vocabulary class. This class was attended by 21 students and it was held on Tuesday starting from 09:00 until 11:00 P.M. Regarding the data 
gathering processes, the researcher distributed the Likert-scale questionnaire asking about the students' perceptions on extensive reading strategy implemented in this vocabulary class. The questionnaire comprised of fifteen statements and the research participants had to select their degrees of agreement by choosing one out of five options namely strongly disagree, disagree, neutral, agree, and strongly agree. After having filled the questionnaire, three research participants were invited to participate in an interview session to answer nine comprehensive questions focusing mostly on their current perceptions regarding the implementation of extensive reading strategy in vocabulary class. After obtaining all of the intended data, the researcher analyzed the data more profoundly to provide clearer findings and discussions regarding the effectiveness of extensive reading strategy applied in vocabulary class. In accord with this step, the researcher attempted to give better enlightenment to shed all of the obtained findings in a narrative way. Connelly and Clandinin (2006) state that narrative inquiry enables the researchers to obtain clearer phenomena occurred in some specific research fields since the authenticity of tangible stories uttered by the research participants gains a higher degree of trustworthiness.

\section{RESULTS AND DISCUSSION}

\section{Extensive Reading Strategy and Students' Vocabulary Knowledge}

The following discussion is attempted to answer the first research question, namely: How did extensive reading strategy employ in the vocabulary class improve students' vocabulary? The data were in the form of classroom survey. The self-reported data clearly suggested that ER strategy: (a) had impact on enjoyment, (b) expanded students' personal theories on literacy, (c) promoted significant vocabulary improvements, and (d) reinforced vocabulary acquisition.

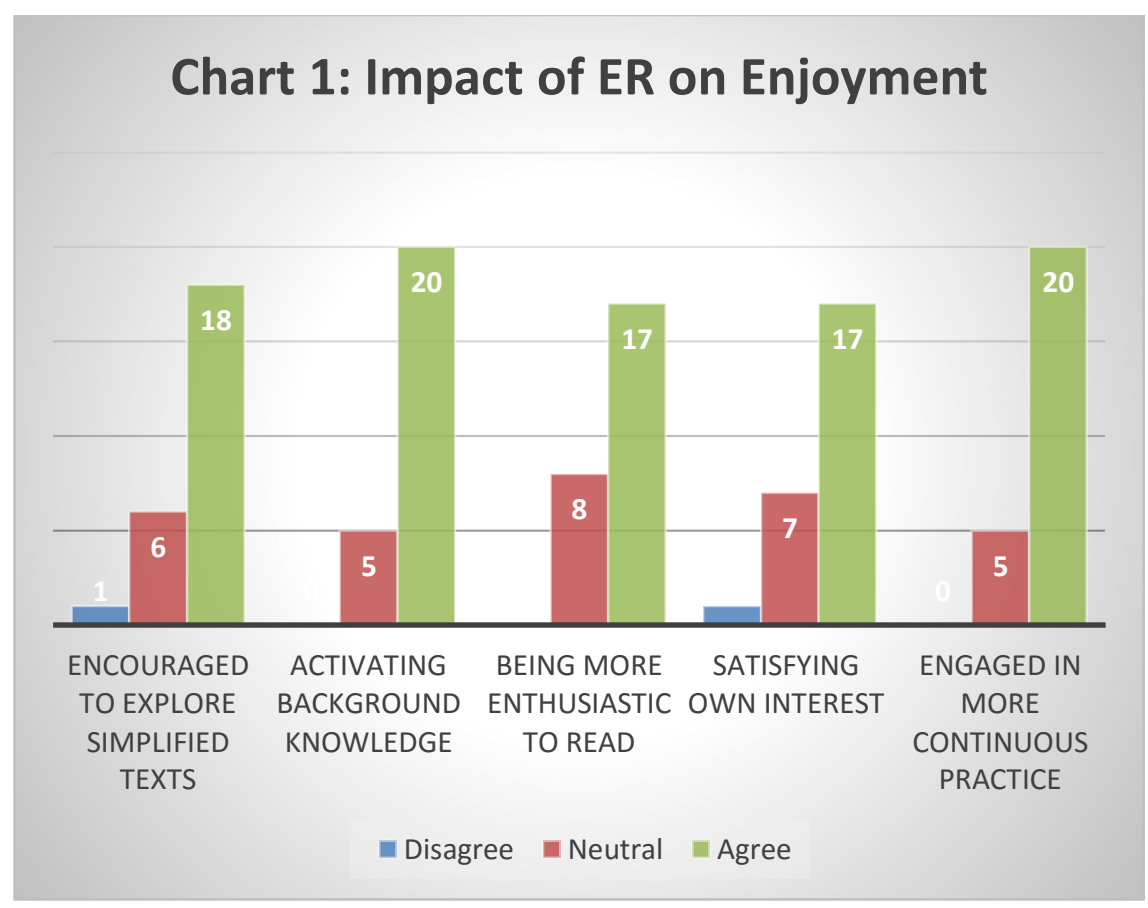

From the data presented above, it can be inferred that extensive reading strategy had promoted a higher degree of enjoyment for English Language Education students engaging in vocabulary class. This contention is evinced by the first finding forming in this chart revealed that 18 out of 25 students agreed that simplified second language texts assisted them to read more fluently and gain a great number of words simultaneously. In this respect, the students had gradually 
improved their word amounts since they heed their attention to the major information presented in their texts without being distracted too extensively by some unknown words. This argument is resonated well with a theory of reading proposed by Day and Bamford (1997) who imply that reading activities can be run more efficiently when the students possess a higher degree of enjoyment in their texts. Parallel with the aforementioned first finding, it is also of critical importance to elucidate the second finding revealed that 20 students agreed that it is indispensable to activate their background knowledge of the topics presented in their texts before commencing in-depth reading activities. This argument indicated that background knowledge played an extremely crucial role in determining the retention of new information and words through current reading dynamics since the students will be able to gain some information and foster their vocabulary knowledge more effectively. This argument is very much in line with the theory of background knowledge by Coady (1979) who states that the continuous activation of background knowledge towards specific themes forming in the texts will assist the students to comprehend the information easily. Following this second finding, 17 students also agreed that an extensive reading strategy allowed them to experience more enjoyment in reading. This third finding has shown that students should be allowed to select particular texts arousing their reading interests most to nurture their excitement in reading continuously. Such an argument is consistent with Krashen (1989). He mentioned that specific texts attracted the students' big interest in reading will stimulate them to read plenty of texts frequently leading them to gain a greater acquisition of vocabulary. In accord with this prior delineation, the fourth finding also highlighted an indispensable nature of free-chosen reading texts since 17 students also agreed that favorite texts had also fulfilled their interests, preferences, and needs in reading. Therefore, it is encouraging to relate this finding with the idea of Bell and Clark (1998) who contend that free reading activities will increase the students' motivation in reading since they can read more enjoyably and efficiently according to the exact text levels they opted for. Given the importance of extensive reading strategy in this first chart, the ultimate finding exhibited the tangible learning outcome after the students engaged in continuous free reading activities. 20 students acknowledged that they had established such a strong volition, persistence, and motivation to read various kinds of second-language texts independently since greater efforts are believed to improve reading competencies and enrich vocabulary knowledge through long-term processes. This finding shared a mutual interconnectedness with Elley (1991) who argues that proficient readers can be engendered only by consistent practices.

\section{Chart 2: Expanding Students' Personal Theories on Literacy}

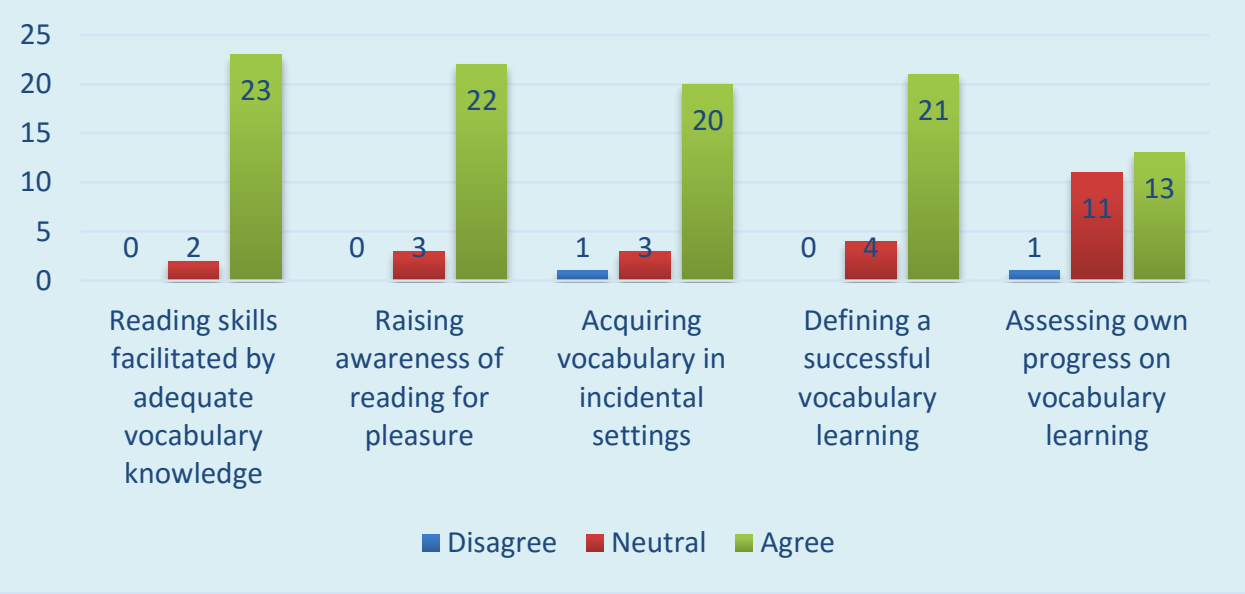


Based on the data shown above, it can be surmised that extensive reading strategy influenced students' theories on literacy. The first finding from this chart points out that 23 students confessed that an adequate amount of vocabulary knowledge helped them to understand the texts more easily since they can interpret each message presented in the passages more accurately. Nation and Coady (1988) believe that vocabulary knowledge played an essential role leading students' success in reading since precise interpretation of the ideas can be done continuously. In light of this first finding, it is also worthwhile to argue that extensive reading strategy can promote a great number of new words for the students as they experience a great pleasure in reading, 22 students had agreed to this second finding. Nagy and Herman (1987) urged the teachers to implement extensive reading strategy while introducing second language texts to students to expand their vocabulary knowledge more greatly.

The successful implementations of extensive reading strategy will transform the students to be more autonomous in their reading activities as indicated in the third finding that 20 students admitted that through incidental settings, they had gradually improved their vocabulary knowledge. This further finding supports the theory of Thornbury (2002), who contends that independent readers possessing a great number of second language words can be breed through continual extensive reading practices. After experiencing a higher degree of enjoyment and taking further initiatives to be more independent readers, it is also wiser to acknowledge that significant vocabulary improvements can be experienced holistically by the students engaging in extensive reading activities when they can create more meaningful vocabulary learning processes concerning their texts. This delineation is shown in the fourth finding as 21 students agreed to the importance of extensive reading strategy regarding their continuous development of reading skills and vocabulary knowledge altogether. This fourth finding is closely interlinked with vocabulary learning theory proposed by Grabe (2009). He argued that extensive reading strategy is intended to develop the students' capacities in both reading skills and vocabulary acquisition. Eventually, the last finding suggested us that assessing vocabulary learning progresses through extensive reading strategy is also pivotal in ensuring the successful acquisition of new words, continuous development of reading comprehension skills, and big excitement in reading. 13 students had shown their agreement to this ultimate finding since they were eager to read a wide array of texts for the benefits of their reading competencies and word knowledge improvements. This fact is supported by the argument evoked by Davies and Stone (1995) who state that through extensive reading, the students can hold a more positive nuance towards reading, enhance their reading comprehension skills, and gain more substantial words.

\section{Chart 3: Significant Vocabulary Improvements Obtained through ER}

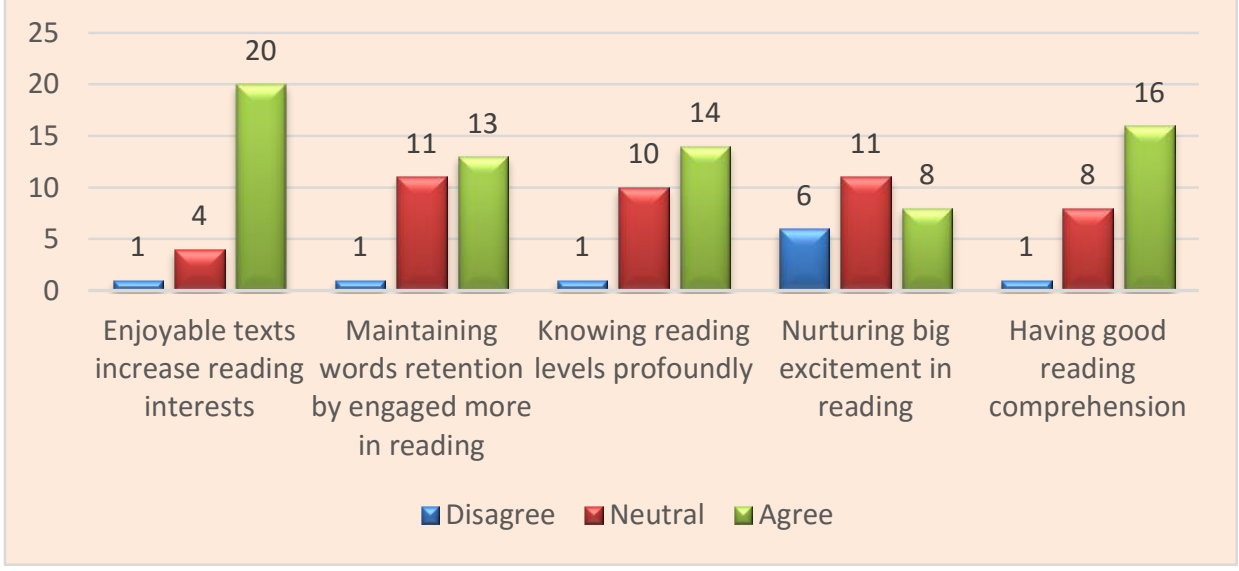


Regarding the obtained data, it can be assumed that most of the students engaging in extensive reading activities had successfully improved their word knowledge. In successfully doing so, the first finding delineated that 20 students confessed that enjoyable reading texts had aroused their reading interests. As stated previously, free reading activities enabled all students to foster their overall reading comprehension and word amounts since they are able to read the chosen texts more easily in relevance to their reading proficiency, interests, and speed. This argument is harmonized with the theory of reading by Day et al, (1998). They believed that free-chosen reading texts allowed the students to interact with the information more efficiently according to their particular reading levels, preferences, and velocity. In the same vein, the second finding revealed that 13 students acknowledged the importance of keep contacting with some new words continuously in order to preserve this word retention everlastingly. In other words, this second finding aimed to suggest us that reading a wide variety of texts is very crucial in maintaining the knowledge of new words stored in our mind since these glossaries will be vanished easily when the students ceased reading. This argument had shared a tight-knit relationship with a seminal theory of vocabulary learning by Nation (1997.), who argues that through continuous reading practices, the students will be able to nurture their vocabulary knowledge and foster their reading skills concurrently. As stated above, to be able to read plenty of texts more easily and efficiently, the students should be commissioned to pick up any kinds of reading texts attracting them most. However, it should be noted that a higher degree of enjoyment in reading can also be ascertained by the appropriate selections of texts conformed with the students' particular reading proficiency. In accord with this conception, 14 students in the third finding admitted that they had acquainted with their reading levels before selecting some reading materials in their class. This finding indicated that the students had already valued reading as a personal consideration, responsibility, and development in correspond to their particular proficiency. Thus, they selected and read their texts according to paramount needs they entailed during the reading processes. In light of the aforementioned perspective, Nation (op.cit.) states that students should view deliberate reading text selections as one pivotal trajectory determining their upcoming development in reading. With this picture in mind, it is also motivating to correlate this previous finding with the fourth finding revealed that there were only 8 students who have successfully nurtured their big excitement in reading. This further finding was surprising since most of the students have fully identified their major strength and weaknesses in reading by selecting the most appropriate texts that work best for them. However, it is important to note here that most of the students participating in this survey also acknowledged that they still depended too extensively on their vocabulary while encountering some unfamiliar words in the texts. This over-addiction on vocabulary will, of course, impede their fluency and eventually degrade a higher degree of excitement in reading. This argument is very much in line with the theory of reading by Koch (2009). He discouraged the students to abandon dictionary while confronting with some difficult words in their texts in order to maintain the consistency of reading fluency, accuracy and enjoyment. In this case, he also suggested that the teachers should encourage the students to consult the meanings of some words with their dictionaries right after finishing their extensive reading activities after knowing these perilous drawbacks. In spite of various advantages and controversies offered by extensive reading strategy, it is also satisfying to refrain here that 16 students have already possessed laudable reading comprehension after taking part in extensive reading activities. This gratifying learning outcome obtained since most of the students acknowledged that they constantly conducted active interactions with the information forming in their texts. In simpler words, the students did not merely receive the messages from the readers passively but also generate some critical inquiries leading them to exercise their critical thinking skills over the specific topics being discussed. Correspondingly, Von Glasersfeld (1989) proclaims that critical learners always possess a comprehensive understanding of the facts permeated in their learning routines 
and they consistently ruminate over that factual information in order to create more meaningful knowledge acquisition for their learning processes (as cited in Tobias and Duffy, 2009).

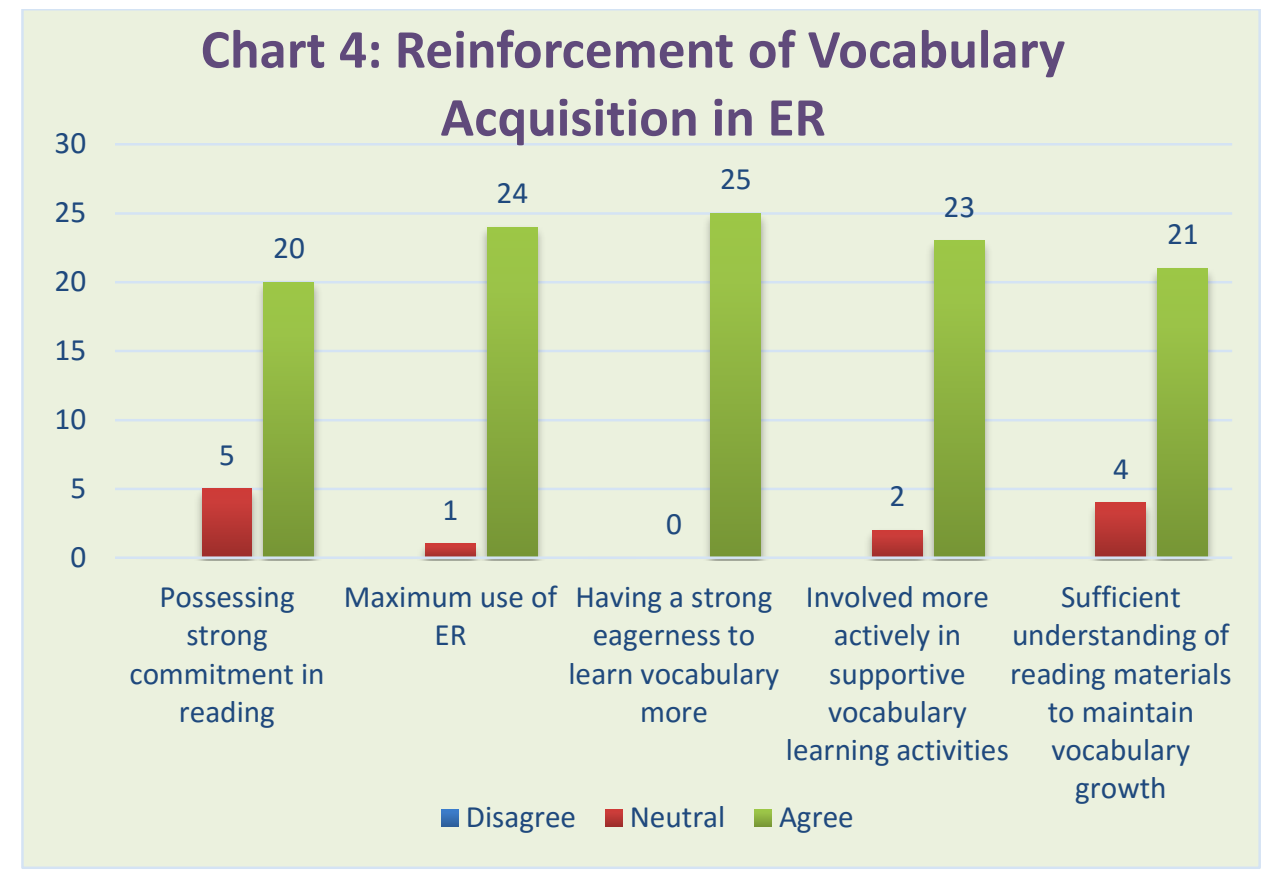

In conformance with the presented data, it can be fairly concluded that most of the students have successfully amplified their vocabulary knowledge through extensive reading activities. It is evident by observing the first finding displaying that 20 students have ingrained more robust volition in reading. Since extensive reading activities demand the students to be more responsible for their learning enterprises, the teachers should be able to ascertain that every student has already possessed a longing to develop their reading competencies and vocabulary capacities into the utmost. In correspond to this argument, Grasersfeld (1989) states that to be successful academicians, the students need to establish a higher degree of responsibility in their learning (as cited in Tobias and Duffy, 2009). To enable all students to reap this laudable learning attitude, it is worth mentioning that the teachers play a crucial role, particularly in executing extensive reading activities. Hence, the teachers have to transform their conventional roles as knowledge transmitters become supportive learning companions and facilitators in the presence of the students. This conception is closely intertwined with the second finding in which 24 students completely agreed that their lecturer had successfully played her role as a faithful learning counterpart in the midst of impediments, adversity, and laborious situations they faced during engaging in extensive reading activities. The important role of instructor is resonated well with an argument emanated from Rhodes and Bellamy (1999). They stated that great learning facilitators always provide some useful trajectories for the students to discover the truth throughout learning dynamics, and create a dialogic conversation with the learners to accompany them continuously in the learning processes. Further, the most surprising finding emanated from the third finding since all 25 students agreed that they have established such a strong desire to learn a wide array of new words after engaging in extensive reading activities. This data had been proved by the fact that the lecturer applying extensive reading strategy in vocabulary class constantly created a safe and enjoyable learning environment for all students to participate. Thus, every students' opinion, idea, argument, and perspective is highly exalted in order to perpetuate a higher degree of enjoyment and liberation of learning. Pertinent to this contention, Di Vesta (1987) states that positive learning circumstances will prompt all students to exercise their thinking in a more conducive way. To give clearer emphasize, the teachers 
have to establish more intimate and positive relationships with their students to design better learning environments where they are able excel their capacities as academicians. This presumption is in tandem with the actual fact occurred during the vocabulary learning activities aligned with the fourth finding. 23 students confessed that they proactively engaged in supportive vocabulary learning activities conducted by the lecturer since she was able to establish a positive rapport with her students by listening to their aspirations, issues, and preferences attentively. The aforesaid argument echoed very much with the theory of social constructivist learning model enacted by Brown et al, (1989). They accentuated on the importance of positive and intimate relationships made between the teachers and students which is believed to arouse both active and effective learning dynamics. After all, it is also worth noting here that the successfulness of the lecturer in incorporating extensive reading strategy in vocabulary class does not only depend on a positive rapport and supportive learning environment grounded well in the lens of collaborative learning dynamics but also ample meaningful learning activities integrated by the lecturer. This last finding shared an affinity with the theory of second language learning advocated by Savery (1994), who argues that wellstructured learning circumstances will ease the students to construct more purposeful thinking framework towards assigned topics.

\section{Five Powerful Ways to Improve Students' Vocabulary}

The following discussion is attempted to answer the second research question, namely: How did extensive reading strategy increase students' vocabulary knowledge? The data gathered was in the form of focus group discussion. The data analysis clearly lead to five powerful ways to improve students' vocabulary: (a) an enhancement of strong reading motivation, (b) a great number of easy reading materials, (c) practicing reading faster continuously, (d) raising high learning awareness, and (e) the significant contributions from an instructor.

\section{a) An Enhancement of Strong Reading Motivation}

An enhancement of strong reading motivation can only be generated if the students experience both enjoyment and comfort when reading their texts. By all means, it is the students who are able to take advantages from their reading activities since they acquire both language skills and aspects through their texts such as reading skills, writing skills, grammar, and vocabulary. The last thing to consider as an important element in language learning for the students is that they will not be able to communicate, listen, read, and write well without possessing a large amount of vocabulary, which will specifically be facilitated through extensive reading. Nation (2009) claims enjoyment and broad knowledge can be found in reading.

Levy (2016) claims that extensive reading favors for independence in reading, and enables the students to read based on their reading speed and proficiency. In brief, all of these theories remind language teachers that positive perspective toward extensive reading need to be corroborated by flexibility in selecting the texts with a purpose enhancing the students' strong reading motivation.

\section{b) A Great Number of Easy Reading Materials}

A great number of easy reading materials are obligatory for the students in order to make them be more engaged in extensive reading. By holding this principle, the students will be eager to read their texts more enthusiastically. As a result, their vocabulary knowledge can be improved more significantly. For this reason, language teachers need to ensure whether the students have 
already recognized most of the words forming in their texts or not. Hu and Nation (2000) state that the students should be familiar with $95-98 \%$ words presenting in their texts with a purpose not giving learning burdens to them in extensive reading.

In order to ensure the students have already familiar with most of the running words in their texts, Coady and Huckin (1997) state that many extensive reading experts suggest that simplified reading texts need to be integrated especially for the students, who are still beginners. Nevertheless, he also recommends that the learners should continue reading more advanced reading materials after mastering their simple texts. This stage is important as the students are able to maintain their vocabulary growth continuously with the help of simple and advanced reading texts.

\section{c) Practicing Reading Faster Continuously}

Reading fluency is another essential element that needs to be integrated into extensive reading since the students are able to read their texts more fluently without spending most of their time to deal with unknown words in the texts. Hence, the students have to practice reading faster continuously in order to strengthen their interests and maintain their fluency in extensive reading.

In order to attain this main objective, language teachers need to employ two beneficial strategies to preserve students' reading fluency and interests as proposed by Nation (2002) namely:

a) Practicing reading faster is believed to improve the amounts of reading done by students and enable them to obtain interests toward what they have read.

b) The students are allowed to avail dictionary with a regard it does not interrupt their reading processes. There are two ways they can do to avoid any kinds of disruptions in extensive reading like taking notes of unknown words on cards and interpret the meanings of new words after finishing reading.

\section{d) Raising High Learning Awareness}

Before taking extensive reading for granted, language teachers have to raise students' high learning awareness in order to make them become more proficient in terms of language aspects and world knowledge. High learning awareness has a tight-knit relationship with constructivism learning theory as the students should be responsible for their own learning by constructing their knowledge independently. By being responsible for their own learning, the students will gain more benefits through the learning processes. In other words, they experience a big success in learning. Savery and Duffy (2001) argue that big learning responsibility needs to be possessed fully by the students in constructivism.

\section{e) The Significant Contributions from an Instructor}

The role of teachers has already changed drastically as the students are required to be responsible for their own learning in extensive reading. Accordingly, the teachers need to be great instructors in the presence of their students. In order to be great instructors, they should be good facilitators first by knowing their students' needs and trying to create various supportive teaching-learning activities functioning as positive learning environments. In order to do so, the teachers need to transform their selves become good role models during the teaching-learning processes. 
In line with this main objective, Day and Bamford (2004) mention two out of ten extensive reading principles how to be great instructors namely:

a) The teacher orients and guides the students: Before making use of extensive reading, the teachers should explain the main objectives of it, why the students have to deal with it, and how to run it successfully. Also, the teachers need to know genres and amount of the texts, which students have read in order to help them obtain the essence of reading.

b) The teacher is a role model of a reader: One of the most promising ways to be great instructors is the teachers need to be involved reading similar texts, which students read. This approach should be done to give some tips for the students how to be effective readers. Last, the teachers can also form an informal reading community where they are able to give suggestions about the texts students should read and experience the outcomes and enjoyment through free reading activities.

\section{CONCLUSION}

Three major conclusions were drawn in this study namely enjoyment, strong reading eagerness, and positive learning atmosphere. The first matter needs to be possessed by students in order to enable them to read their selected texts more enthusiastically. Enjoyment can also lead the students to strong reading eagerness. As the students find the reading materials are pleasurable and suitable with their learning needs, they will always have strong intention to read as many texts as possible. These two factors create a positive learning atmosphere for the students since they shape a better understanding of their texts and discover that free reading activities giving them a rewarding experience in terms of the significant improvements of world knowledge, reading skills, and most importantly vocabulary knowledge. This study could also expand the body of works that examine the effectiveness of various reading types implemented in vocabulary class to improve EFL learners' vocabulary knowledge. Therefore, it is worthwhile to be suggested that future researchers need to conduct more exhaustive investigations on extensive reading strategy implemented in other discipline-specific aspects of second language learning namely grammar, pronunciation. This future investigation will be the paramount of importance for further development of extensive reading strategy due to its applicability in other essential target language specific fields.

\section{ACKNOWLEDGMENTS}

The researcher would like to extend his deepest gratitude for all parties taking part for the successfulness of this study. Special thanks are also addressed to Miss. Laurentia Sumarni S.Pd., M.Trans. St., gave a permission for the researcher to conduct this study. The researcher also addressed his profound thankfulness for all 25 English Education Students who are willing to participate actively and cooperatively in this study. Without this cooperation, this study will not be finished on time. Further, this study is not without its limitations since it was only a small-scale study conducted in a small vocabulary classroom circumstance. Thus, the researcher suggested that future studies should be undertaken to conduct more exhaustive investigations in greater depth about the implementations of extensive reading strategy in other second language classes alike reading, critical reading and writing, and introduction to literature to disseminate gigantic impacts on the upcoming second language learning ventures. 


\section{REFERENCES}

Alqahtani, M. (2015). The Importance of Vocabulary in Language Learning and How to be Taught. International Journal of Teaching and Education, 3(3), 21-34.

Anwar, Y. T., \& Efransyah, E. (2018). Teaching English Vocabulary Using Crosswords Puzzle Game at The Seventh Grade Students. PROJECT (Professional Journal of English Education), 1(3), 235-240.

Bamford, J., \& Day, R. R. (1997). Extensive reading: What is it? Why bother? Language Teacher-Kyoto-Jalt-, 21, 6-8.

Bell, Y. R., \& Clark, T. R. (1998). Culturally relevant reading material as related to comprehension and recall in African American children. Journal of Black Psychology, 24(4), 455-475.

Benettayeb, A. (2010). Extensive Reading and Vocabulary Teaching. Revue Academique des Etudes Sociales et Humaines. 3(1), pp. 20-30. Retrieved from http://web.univ-chlef.dz

Brown, J. S., Collins, A., \& Duguid, P. (1989). Situated cognition and the culture of learning. Educational researcher, 18(1), 32-42.

Coady, J. (1979). A psycholinguistic model of the ESL reader. Reading in a second language, 5-12.

Connelly, F. M., \& Clandinin, D. J. (2006). Narrative inquiry. Handbook of complementary methods in education research, 3, 477-487.

Davies, M., \& Stone, T. (1995). Mental Simulation: Evaluations and Applications-Reading in Mind and Language. Oxford: Blackwell.

Day, R. R. (2015). Extending Extensive Reading. Reading in a Foreign Language. 27(2), pp. 294-301. Retrieved from https://files.eric.ed.gov/

Day, R. R. and Bamford, J. (2004). Extensive Reading Activities for Teaching Language. Cambridge: Cambridge University Press.

Day, R. R., Bamford, J., Renandya, W. A., Jacobs, G. M., \& Yu, V. W. S. (1998). Extensive reading in the second language classroom. RELC Journal, 29(2), 187-191.

Di Vesta, F. J. (1987). The cognitive movement and education. In Historical foundations of educational psychology (pp. 203-233). Springer, Boston, MA.

Elley, W. B. (1991). Acquiring literacy in a second language: The effect of book-based programs. Language learning, 41(3), 375-411.

Gardner, D. (2004). Vocabulary Input through Extensive Reading: A Comparison of Words Found in Children's Narrative and Expository Reading Materials. Applied Linguistics. 25(1), pp. 1-37. Retrieved from https://academic.oup.com

Gayanti, R., \& Satriani, I. (2020). Teaching Students' Vocabulary Through Total Physical Response. PROJECT (Professional Journal of English Education), 3(3), 414-419.

Grabe, W. (2009). Reading in a second language: Moving from theory to practice. Ernst Klett Sprachen.

Hu, H. M., \& Nation, P. (2000). What vocabulary size is needed to read unsimplified texts. Reading in a foreign language, 8, 689-696.

Koch, T. (2009). Expanding the power of extensive reading: Avoiding the rabbit hole. Selected papers on theoretical and applied linguistics, 18, 193-198.

Krashen, S. (1989). We acquire vocabulary and spelling by reading: Additional evidence for the input hypothesis. The modern language journal, 73(4), 440-464.

Levy, L. S. (2016). Extensive Reading in English as a Foreign Language/English as a Second Language Contexts. Reports from the Faculty of Clinical Psychology. 9, pp. 69-85. Retrieved from https://www.kbu.ac.jp 
Moretti, G., \& Alessandrini, G. (2015). Community of Practice and Teacher's Professional Development: An Explorative Survey. Journal of Educational, Cultural and Psychological Studies (ECPS Journal), (11), 253-273.

Nagy, W. E., Anderson, R. C., \& Herman, P. A. (1987). Learning word meanings from context during normal reading. American educational research journal, 24(2), 237-270.

Nation (2002). Managing Vocabulary Learning. Singapore: SEAMEO Regional Language Centre.

Nation, I. S. P. (2009). Language Curriculum Design. New York: Routledge.

Nation, P. (1997). The language learning benefits of extensive reading.

Nation, P., \& Coady, J. (1988). Vocabulary and reading. Vocabulary and language teaching, 97, 110.

Nurdiansyah, D. M. R., Asyid, S. A., \& Parmawati, A. (2019). Using Color Coding To Improve Students'english Vocabulary Ability. Project (Professional Journal Of English Education), 2(3), 358-363.

Parmawati, A. Using Magic Sentences Technique To Improve Students'vocabulary (Classroom Action Research In The First Semester Students Of Ikip Siliwangi Bandung).

Rhodes, L. K., \& Bellamy, G. T. (1999). Choices and consequences in the renewal of teacher education. Journal of teacher education, 50(1), 17-26.

Savery, J. R., \& Duffy, T. M. (2001). Problem Based Learning: An Instructional Model and Its Constructivist Framework. Center for Research on Learning and Technology: Indiana University.

Savery, L. K. (1994). Attitudes to Work: The Influence of Perceived Styles of Leadership on a Group of Workers. Leadership and Organization Development Journal, 15(4), 12-18.

Thornbury, S. (2002). How to teach vocabulary. England.

Tobias, S., \& Duffy, T. M. (2009). The success or failure of constructivist instruction: An introduction. In Constructivist Instruction (pp. 15-22). Routledge. 